Alal MLE.

PPPL-2758

UC-420,421,423
PPPL-2758

\title{
DISCHARGE CLEANING ON TFTR AFTER BORONIZATION
}

BY

\author{
D. MUELLER ET AL
}

Miaj 1991
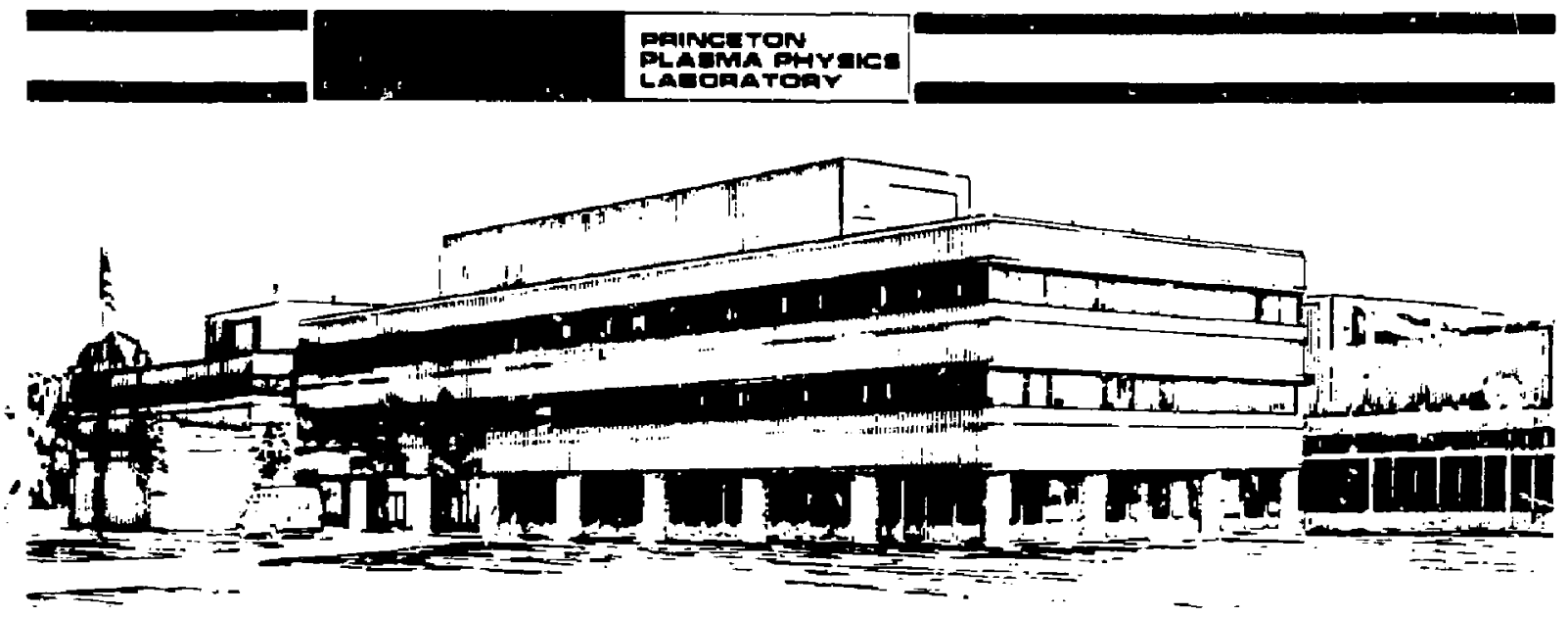

\section{PRINCETON UNIVERSITY, PRINCETON; NEW' JERSEYY}




\section{NOTICE}

This report was prepared as an account of work sponsored by an agency of the United States Government. Neither the United States Government nor any agency thereof, nor any of their employees, makes any warranty, express or implied, or assumes any legal liability or responsibility for the accuracy, completeness, or usefulness of any information, apparatus, product, or process disclosed, or represents that its use would not infringe privately ow'ned rights. Reference herein to any specific commercial produce, process, or service by trade name, trademark, manufacturer, or otherwise. does not necessarily constitute or imply its endorsement, recommendation, or favoring by the United States Government or any agency thereof. The views and opinions of authors expressed herein do not necessarily state or reflect those of the United States Government or any agency thereof.

\section{NOTICE}

This report has been reproduced directly from the best available copy.

Available to DOE and DOE contractors from the:

Office of Scientific and Technical information

P.O. Box 62

Oak Ridge, TN 37831 ;

Prices available from (615) 576-8401.

Available to the public from the:

National Technical Information Service

U.S. Department of Commerce

5285 Port Royal Road

Springfield, Virginia 22161

$703-487-4650$ 
D. Mueller, H. F. Dylla, P. H. LaMarche, M. G. Bell, W. Blanchard, C. E. Bush, C. Gentile, R. J. Hawryluk, K. W. Hill, A. C. Janos, F. C. Jobes, D.K. Owens, G. Pearson,

J. Schivell, M. A. Ulrickson, C. Vannoy and K. L. Wong

\author{
Princeton Plasma Physics Laboratory \\ Princeton University \\ Princeton, N.J. 08544
}

\begin{abstract}
Accepted for Publication
in the

Journal of Vacuum Science and Technology

1991
\end{abstract}




\section{DISCHARGE CLEANING ON TFTR AFTER BORONIZATION*}

D. Muelter, H. F. Dyllat, P. H. LaMarche, M. G. Bell, W. Blanchard, C. E. Bush, C. Gentile, R. J. Hawryluk, K. W. Hill, A. C. Janos, F. C. Jobes, D. K. Owens, G. Pearson, J. Schivell, M. A. Ulrickson, C. Vannoy and K. L. Wong

\section{Princeton Plasma Physics Laboratory}

P.O. Box 451

Princeton, Now Jersey 08544

†Present address CEBAF Center, 12000 Jefferson Ave, Newport News, VA. 23606

\section{ABSTRACT}

At the beginning of the 1990 TFTR experimental run, after replacement of POCO-AXF-5Q graphite tiles on the midplane of the bumper limiter by carbon fiber composite (CFC) tiles and prior to any Pulse Discharge Cleaning (PDC), boronization was performed. Boronization is the deposition of a layer of boron and carbon on the vacuum vessel inner surface by a glow discharge in a diborane, methane and helium mixture. The amount of discharge cleaning required after boronization was substantially reduced compared to that which was needed after previous openings when boronization was not done. Previously, after a major shutdown, about $10^{5}$ low current ( 20 kA) Taylor Discharge Cleaning (TDC) pulses were required before high current ( $400 \mathrm{KA})$ aggressive Pulse Discharge Cleaning (PDC) pulses could be performed successfully. Aggressive PDC is used to heat the limiters from the vessel bakeout temperature of $150^{\circ} \mathrm{C}$ to $250^{\circ} \mathrm{C}$ for a period of several hours. Heating the limiters is important to increase the rate at which water is removsi from the carbon limiter tiles. After boronization, the number of required TDC pulses was reduced to $<5000$. The number of aggressive PDC pulses required was approximately unchanged. 


\section{INTRODUCTION}

We discuss the conditioning of TFTR following the February - March 1990 vacuum vessel opening and compare it to data from 1986 - 1988 discussed previously. 1-6 During the February - March 1990 opening, POCO-AXF-5Q graphite tiles on the middle six rows, about $7 \mathrm{~m}^{2}$, of the $20 \mathrm{~m}^{2}$ bumper limiter were replaced with carbon fiber composite (CFC) tiles. This material has higher stress limits than sintered graphite7. This replacement was expected to ameliorate problems previously encountered due to damage to some of these bumper limiter tiles which resulted from high thermal stress during plasma disruptions. In the past, after a vacuum opening, initial conditioning was accomplished by glow discharge cleaning (GDC), followed by low current ( 20 kA) Taylor Discharge Cleaning (TDC), high current ( $400 \mathrm{kA})$ aggressive Pulse Discharge Cleaning (PDC) and finally by Disruptive Discharge Cleaning (DDC) as described in Refs. 1-6. Following the February - March 1990 opening, the same procedure was followed except that between GDC and TDC, a boron and carbon layer about $100 \mathrm{~nm}$ thick was deposited on the internal surtaces by a glow discharge in a diborane, methane and helium mixture $8-11$. This boronization was followed by a GDC in He to help remove some of the hydrogen deposited with the boron and carbon film. This paper builds on Ref. 1 which concentrates on a discussion of the criteria used to determine when sufficient discharge cleaning has been performed to permit high power operation. As in Ref. 1, the term conditioned will be taken to mean that, as a minimum: 1) operation of TFTR at plasma current ( $\left.I_{p}\right)$ up to 2 MA can be accoinplished and 2) recovery from a disruption by production of another cischarge in a few attempts is possible. In general, lack of conditioning is believed to arise from either of two causes: 1) outgassing of hydrogenic species from the limiter surface which causes high plasma density and 
increased resistivity early in the discharge, or 2) oxygen contamination that causes a radiation collapse of the discharge. 12

\section{GLOW DISCHARGE CLEANING}

For initial machine conditioning the TFTR vacuum vessel is baked at $150{ }^{\circ} \mathrm{C}$ for several weeks. During this time period, approximately 50 hours of GOC5 in flowing deuterium is performed. Two anodes are inserted into the machine extending $=1 \mathrm{~m}$ from the wall and are located at roughily opposite points on the machine. Deuterium (or helium) gas is pressure controlled to 0.7 $\mathrm{Pa}(5 \mathrm{mTorr})$ and the glow is performed at $\approx 250 \mathrm{~V}$, drawing $15 \mathrm{~A}$. This procedure is particularly effective in removing gross hydrocarbon contamination but somewhat less effective at removing adsorbed water. 13

\section{BORONIZATION}

Given the significant improvement in machine conditioning following boronization performed during the previous operational period, 8 boronization $9,10,11$ was undertaken in the initial conditioning phase (after GDC). It was anticipated that an increase in the machine pumping speed of water due to the hygroscopic nature of the films deposited during boronization would entance the performance of PDC and reduce the time (number of TDC shots) necessary to achieve high power plasma discharge operation. A mixture of $10 \%$ diborane $\left(\mathrm{B}_{2} \mathrm{H}_{6}\right), 2 \%$ methane $\left(\mathrm{CH}_{4}\right)$ and $88 \%$ helium replaces the deuterium (or helium) gas in a glow discharge as described above. The reaction products striking the walls deposit an amorphous film consisting of boron, carbon and hydrogen. The film thickness is estimated to be $100 \mathrm{~nm}$ by monitoring the drop in pressure of the supply cylinder and assuming all the diborane ( 1.8 moles in this case) was deposited over the $200 \mathrm{~m}^{2}$ torus. Unlike 
the previous boronization events, this deposition was performed during the bake out period with the vacuum vessel heated to $150^{\circ} \mathrm{C}$.

Immediately after boronization no attempt to make normal discharges was made. However, from the description of the PDC that follows, there is evidence that normal high power pulsing (HPP) on TFTR could have been accomplished after the He GDC following bornization.

\section{PULSE DISCHARGE CLEANING}

POC is performed in two modes with the vacuum vessel at $150^{\circ} \mathrm{C} .^{1}$ The first mode, TDC, is performed in $D_{2}$ with prefill pressure of 0.05 to 2 Pascal, a toroidal field (TF) of 0.2 Tesla and an applied loop voltage of about 60 V/turn. This produces short $(50 \mathrm{msec})$ discharges with $I_{p}$ of $15-50 \mathrm{kA}$. The primary benefit of TDC is to remove oxygen from the vacuum vessel. The second mode, aggressive PDC, is performed with a lower $\mathrm{D}_{2}$ prefill of about $5 \times 10^{-3} \mathrm{~Pa}$ and a higher TF of about 0.7 Tesla which permit lower loop voltage to be used (35 V/turn). The ohmic heating (OH) power supplies, used in conjunction with the $\mathrm{OH}$ capacitor bank, increase Ip $10400 \mathrm{kA}$ limited by $\mathrm{q}=$ 3 disruptions and increase the pulse duration to about $400 \mathrm{~ms}$. In contrast, with the higher prefill pressure and lower TF used in TDC, the discharge terminates at $\quad 35 \mathrm{~ms}$ even if the $\mathrm{OH}$ power supplies aro employed in an attempt to increase $I_{p}$ and the discharge duration.

In the past we have found that, following a major vessel opening, about $10^{5}$ TDC puises were required before it was possible to make effective aggressive PDC pulses. Aggressive PDC attempted after fewer TDC pulses either failed to reach a plasma current of about 400kA or prcduced large bursts 
of hard $\mathrm{x}$-rays indicating the presence of runaway electrons. These premature attempts at aggressive PDC also failed to produce substantial heating of the graphite bumper limiter. In the past, it was not possible to produce normal high power discharges before effective PDC could be accomplished. After about $10^{5}$ TDC pulses, aggressive PDC was possible and a few hours of continuous aggressive PDC pulsing at a repetition rate of about $1 / 4.5 \mathrm{sec}^{-1}$ heated the bumper limiter to about $250^{\circ} \mathrm{C}$. The bumper limiter temperature is administratively limited to $250^{\circ} \mathrm{C}$ to limit thermal stresses in the machine.

It was anticipated that the oxygen gettering capability of the hygroscopic boron and carbon film would resuce the need for TDC. In fact, during the 1990 cleanup campaign, and after boronization, the number of TDC shots required was greatly reduced. About six hours of effective aggressive PDC was accomplished before TDC was undertaken. The production of effective aggressive PDC prior to $\sim 10^{5}$ TDC pulses had never been possible following any of the major vacuum vessel openings prior to boronization. During this six hours the quality of the PDC pulses slowly deteriorated, evidenced by increasing hard $X$-ray levels and lower $\mathrm{lp}$. This early aggressive PDC raised the bumper limiter to $230^{\circ} \mathrm{C}$.

It should be noted that this early aggressive PDC was done without the benefit of the pumping provided by the cryopanels of the TFTR neutral beam injectors since all of the neutral beam valves were closed. The vessel pumping time constant, $\tau_{v}$, of the vessel was about $10 \mathrm{~s}$. With the beam valves open the pumping afforded by cryopanels reduces $\tau_{v}$ to $\sim 1 \mathrm{~s}$. In the past we have found that this additional pumping is needed to make prolonged ( $>4$ hours) effective PDC pulsing possible. 
After this early PDC, 5000 TOC pulses were performed with the neutral beam valves closed. Then, one neutral beam valve was opened, reducing $\tau_{v}$ $-2 \mathrm{~s}$, and aggressive PDC was performed. This time the aggressive PDC effectively heated the bumper limiter to $250^{\circ} \mathrm{C}$ in about 2 hours and the bumper limiter temperature was kept there for 8 hours by running at a reduced pulse repetition rate before PDC was declared complete. It is likely that had the neutral beam cryopumping been available at the onset of PDC, no TDC would have been required. Furthermore, since the ability to produce effective aggressive PDC pulses immediately after boronization existed, it seems possible that normal operation could have commenced without any PDC. See Table I for a comparison of the number of conditioning pulses required after the 1989 and 1990 TFTR openings.

\section{DISRUPTIVE DISCHARGE CLEANING}

After PDC, we have found that it is necessary to further condition the limiter by producing intentional disruptions at successively higher plasma currents. ${ }^{14}$ Beginning at 0.6 MA, a disruption is forced by moving the plasma quickly inward to decrease the major and minor radil until a low-q disruption occurs. After recovery, this process is repeated until recovery from the disruption can be achieved in one or two discharges. The plasma current is then increased by 0.2 MA and the procedure is repeated. The primary benefit of this DDC is to heat the surface of the limiter to $>300^{\circ} \mathrm{C}$, the temperature at which water becomes more mobile in graphite, and thereby reduce the oxygen availabie to the plasma. In the past we have proceeded up in current until recovery from 2 MA disruptions is achieved. However, in this campaign we stopped DDC after recovery from 1.4 MA disruptions. There were two reasons for this: 1) it was believed that the improved disruption recovery due to boronization ${ }^{2}$ would 
make it unnecessary to perform as much DDC and 2) there was a cesire to minimize possible damage to the newly installed CFC tiles until we were able to evaluate the supershot performance with the new tiles in place. Immediately after DDC, the recycling coefficient of hydrogenic species is high $(R \equiv 1)$. DDC is therefore followed by ohmic discharges fueled with only helium prefill to deplete the near surface region of the limiter of hydrogenic species and reduce R to about 0.6. This He conditioning is described in detail in Refs. 5 and 14.

\section{CONCLUSIONS}

Boronization effectively reduced the required TDC on TFTR from about $10^{5}$ to $5 \times 10^{3}$ pulses. Consequently, the time devoted to TDC was reduced from about 2 weeks to 8 hours. We believe that the reduction in the amount of discharge cleaning required is due to the oxygen pumping provided by the hygroscopic boron-carbon film deposited during boronization. This represents significant time and cost savings. It is possible that no PDC is required after boronization, but this hypothesis is as yet untested.

"This work supported by U.S. DoE Contract No. DE-AC02-76-CHO3073. 
Table I. Comparison of Cleanup in TFTR after 1989 and 1990 Vacuum Vessel Openings

Troe of Pulse

TDC

PDC

DDC

DDC to 1.4 MA recovery
Pulses in 1989

$8.8 \times 10^{4}$

$1.9 \times 10^{4}$

300

117

\section{Pulses in 1990}

$$
5 \times 10^{3}
$$

$1.1 \times 10^{4}$

75

75 


\section{REFERENCES}

'D. Mueller et al., in Proc of the AVS Conference on Sunface Conditioning of Vazunm Systems (Los Angeles, May 1989), (AIF, N.Y. 1990) AIP Cont. Proc. No. 199, p. 30-38.

${ }^{2}$ H. F. Dylla et al., J. Nucl. Mater. 128/129, 861 (1984).

3H. F. Dylla, W. R. Blanchard, F. B. Krawch!:k, R. J. Hawryluk and D. K. Owens, J. Vac. Sci. Technu!. A2, 1188 (1984).

$4 H$. F. Dylla A et al., J. Nucl. Mater. 145/146, 48 (1987).

5P. H. LaNierrhe et al., J. Nucl. Mater. 145/146, 781 (1987).

6H. F. Dyila and tha TFTR Te am, in Proc. 8th Intern Conf, on Plasma Surface Interactions in Controlled Fusion Devices (Jülich, May 1986), J. Nuci. Mater., 162/164, 128 (1989).

7G.W. Baines, D. K. Owens, G. D. Loesser, ar:d M. Ulrickson, in Proc. of the 13th Sympesium on Fusien Engineering (Knoxville, Oct. 1989); Nucl. Fusion (to be publish€d).

${ }^{8}$ H.F. Dylla, M.G. Bell, R.J. Hawryluk et al., in Proc. gth Inter Conf un Plasma Surface Interactions, (Bournemouth, UK, 1990) J. Nucl. Mater., in press.

9]. Winter, et. al., J. Nucl. Mat. 162-164, 713 (1989).

$10 \mathrm{~W}$. Poschenrieojon, Proc 9th inter Conf. Plasma Surface Interactions. (Bournemonth, U.K., 1990) J. Nucl. Mater., in press.

11P.H. LaMarche, G.R. Walton, E.D. Perry et al., Proc. 16th Symp. on Fusion Technology, (London, UK, 1990), in press.

1ิ̂R. J. Hawryluk and J. A. Schmidt, Nucl. Fusion 16, 775 (1979).

13H.F. Dylla, J. Vac. Sci. Technol. A6, 1276 (1988).

${ }^{14}$ H. F. Dylla et al., Nucl. Fusion 27, 1221 (1967). 